\title{
REITERAÇÃO E DESCONSTRUÇÃO DE UM MODELO: O IMAGEM DE CRISTO N'A DEMANDA DO $S A N T O$ GRAAL E EM O FÍSICO PRODIGIOSO, DE JORGE DE SENA
}

Márcio Ricardo Coelho Muniz

Pesquisador do CNPq

1.

Figura exponencial da cultura do Ocidente, Jesus Cristo é personagem recorrente na literatura do mundo cristão, modelo perfeito dos mais altos ideais que as sociedades são capazes de vislumbrar. Destaca-se em sua caracterização o aspecto ambivalente de sua constituição: Cristo é "ao mesmo tempo homem, no legítimo e autêntico sentido da palavra, e bem mais do que um homem, um ser divino, o Filho de Deus” (DABEZIES, 1998, p.517). Esta ambivalência foi consagrada no Concílio de Calcedônia, em 453. Dependendo do momento e dos interesses em jogo, um desses aspectos será ressaltado pelo grupo social.

Conforme aponta Dabezies, os primeiros cristãos interessaram-se mais pela divindade, pelo caráter transcendental da figura de Cristo. No entanto, com o processo de individuação que a sociedade medieval viveu após a reforma gregoriana, no século XI, foi a humanidade de Cristo o aspecto que passou a interessar. O que esta divindade possuía de próximo ao homem comum e os exemplos de conduta individual que transmitia foram os dados que começaram a despertar atenção nesse período.

A reforma eclesiástica promovida pelo Papa Gregório VII (1073-1085) sintetizava o caráter das modificações por que a sociedade e a Igreja passavam. Foram dois os aspectos centrais da reforma: o primeiro, de motivação política, buscava diminuir a interferência dos leigos nos assuntos da Igreja; o segundo, o mais importante, era de teor moral. Gregório preocupou-se particularmente 
em corrigir hábitos e práticas religiosas. A condenação da simonia e das violações do celibato foram os pontos centrais de seu desejo de mudança.

Da reforma gregoriana e, de certa forma, paralela a esta, veio o grande desenvolvimento da vida monástica que o séc. XII presenciou. A vida de enclausuramento cenobítico que as ordens beneditinas pregavam fortalecia aqueles aspectos defendidos por Gregório VII. Ao mesmo tempo que propiciava uma melhor e maior ascese espiritual, a vida cenobítica protegia-as das interferências políticas e fortalecia a imagem de pureza, castidade, rigidez moral etc. que se desejava para a Igreja. A influência que ordens como as de Cluny e Cister exerceram e a admiração que despertaram nos homens leigos, assim como os favores que conseguiram destes, corroboram o quanto estava certo o Papa Gregório VII.

Todavia, os favores dos leigos fizeram com que as ordens beneditinas crescessem em demasia, cedendo ao luxo material e paulatinamente afastando-se dos ideais de humildade, bondade e pureza que estavam na base do pensamento de São Bento, inspirador daquelas ordens. Além disso, os leigos viam no despertar para a espiritualidade e no negar os prazeres terrenos o grande valor das ordens monásticas. E não só a admiravam como a desejavam. O modelo de busca da ascese espiritual desenvolvido pelos monges em seus enclausuramentos era ao que aspiravam poder seguir, de forma individual, os homens da época. $\mathrm{O}$ grande desenvolvimento do eremitismo não só entre religiosos, mas principalmente entre leigos, denuncia a aspiração ascética que movia esses homens e a ambição por uma vida espiritual individual. Exortava-se por um retorno aos ideais dos primeiros apóstolos, por uma vita apostolica, uma vita angelica.

Neste sentido, os ideais de "pobreza evangélica", "amor caritativo" e "proselitismo" defendidos pelas Ordens Mendicantes (BOLTON, 1986, p. 78) vinham ao encontro dos anseios espirituais do homem do século XII. Os "Frades Pregadores" e os "Frades Menores", de certo modo, representaram uma "reforma” dentro da Reforma Gregoriana.

Para a Igreja elas representavam uma resposta ordenada - regida pela obediência hierárquica e orientada pelos verdadeiros valores cristãos - aos movimentos heréticos que desabrochavam por todos os cantos da Europa. Ao mesmo tempo, aqueles mesmos ideais, somados à constante peregrinação e 
ao comportamento exemplar, vinham ao encontro daquilo que todos desejavam, ou seja, religiosos com vida modelar e dispostos a retomar a orientação evangelizadora dos primeiros apóstolos, preocupando-se em particular com as classes menos favorecidas da sociedade. $\mathrm{O}$ cristocentrismo defendido pelos Frades Mendicantes, em particular pelos Franciscanos, repõe no centro da questão espiritual o exemplo modelar e evangelizador de Cristo.

É dentro deste contexto de reforma e de individualização espiritual que a tradução portuguesa d"A demanda do Santo Graal foi produzida. ${ }^{1}$ Este ensaio pretende demonstrar que não é aleatório que a caracterização do herói da DSG aproxime-o de tal forma da figura de Cristo que, em alguns momentos, deixe a impressão de que se fala do próprio Cristo. Outrossim, pretendemos observar de que forma Jorge de Sena, poeta e prosador português do séc. $\mathrm{XX}$, em sua novela $O$ físico prodigioso, retoma o modelo utilizado na DSG para desconstruí-lo, por meio do erotismo.

2.

Conforme explicita Dabezies, diversas são as maneiras de "transposições simbólicas" da figura de Cristo dentro da cultura literária: o escritor pode trazê-la para a atualidade ou para um passado próximo em que Ele ainda desempenhe um papel moralizador, de corretor dos vícios sociais; ou pode transportá-la para os nossos dias e tentar imaginar como Jesus viveria hoje; ou ainda, associar a figura de Cristo a uma coletividade oprimida, que sofre as injustiças do mundo (DABEIZIES, 1998, p. 521). Enfim, há, segundo o autor, uma espécie de "cristologia poética" que possibilita que a figura mítica de Cristo seja atualizada de variadas formas.

Acompanhando, primeiramente, o percurso de Galaaz pela DSG conseguimos levantar as semelhanças entre ele e Cristo, de quem é "sergente". De início, a descrição, por parte do ermitão que o acompanha, de sua origem e dos porquês de sua escolha por Deus deixa claro a sua predestinação:

O texto d"A demanda do Santo Graal a que temos acesso hoje, em sua tradução portuguesa, deriva de uma segunda versão daPost-Vulgata ou Pseudo Boron. A cópia é, provavelmente, do início do séc. XV e a tradução pode remontar à metade do século XIII (MEGALE, 1988). A partir deste momento A demanda do Santo Graal, por motivo de concisão, será designada por DSG. 
-Filho, cousa santa e honrada, frol e louvor de todos os menios, outorga-me, se te praz, que te faça companha em todo minha vida mentre te puder seguir dê que te partires da côrte del-Rei Artus, ca eu bem sei que nom morarás i mais de uu dia ca a demanda do Santo Graal se começará tanto que tu i chegares (...) Ca Deus, que te fez nascer em tal pecado como tu sabes, por mostrar seu grande poder, essa gram virtude te outorgou per sua piedade e pola bõa vida que tu começaste de tua meninice atá aqui que te dará poder e força e bondade de armas e de ardimento sobre todolos cavaleiros que nunca trouxeram armas no regno de Logres, assi que tu darás cima a todalas outras maravilhas e aventuras $u$ todolos outros falecerom e falecerám. E por em quero todos os teus feitos saber que acabarás, que foste feito em tal pecado, u os outros nom poderom hi aviir, que foram feitos em leal casamento. Eu te quero teer campanha como sei que em nosso tempo nunca fez tam fremoso milagres Nosso Senhor, nem tam conheçudos como fará por ti (p. 21- 22). ${ }^{2}$

De imediato, ficamos sabendo que a Demanda só começará com a chegada de Galaaz e que ele dará cima a "todalas outras maravilhas e aventuras $u$ todolos outros faleceram e falecerám". ${ }^{3}$ Da mesma maneira, o fato de ele ter sido preferido, apesar de ser fruto do pecado, preterindo-se outros cavaleiros, frutos de "leal casamento", deve-se à escolha divina que deseja, através de Galaaz, pecaminosamente concebido, ${ }^{4}$ demonstrar todo seu grande

2 Todas as citações do texto da DSG dar-se-ão pela edição preparada por Irene Freire Nunes, indicada nas referências bibliográficas, ao final deste trabalho. Indicaremos, ao fim de cada citação, entre parêntesis, apenas a página em que esta se encontra.

3 Em obra de cariz sociológico, Heitor Megale não deixa de reconhecer esse caráter de predestinação de Galaaz. O crítico chama atenção para o fato de que apesar de Galvam ter feito o juramento e todos os cavaleiros seguirem-no de imediato, a demanda não se inicia. Espera-se pelo cavaleiro eleito. Da mesma forma, enquanto todas as missões que este deve cumprir não são terminadas, o reino de Artur mantém-se, como se fosse o cavaleiro Galaaz um “anteparo”, a segurança do reino. Exatamente por isso, no momento e $m$ que este morre, se inicia a derrocada daquele, já que não tem mais quem o defenda e sustente (Cf. MEGALE, p.1992).

4 Neste ponto, Galaaz se difere de Cristo, concebido por uma virgem imaculada. No entanto, deste se aproxima pela peculiaridade do nascimento de ambos. O ser gerado por uma virgem distingue Cristo de seus contemporâneos, assim como Galaaz diferencia-se de seus pares, entre outras coisas, pela origem pecaminosa. 
poder e sua grande virtude. ${ }^{5}$ Como se vê, ele é o eleito, que vem ao mundo cumprir a missão de demonstrar o poder de Deus, assim como Cristo.

A condição de escolhido, de eleito, é constantemente reiterada ao longo da obra. Logo à sua chegada à Távola Redonda, o ermitão que o acompanha revela sua filiação à linhagem a que pertence o próprio Cristo: “_ Rei Artur, eu te trago o cavaleiro desejado, aquel que vem do alto linhagem del-rei David e de Josep Baramatia, per que as maravilhas desta terra e das outras haverám cima” (p. 29). No episódio do Escudo, o ermitão ao referir-se à Galaaz, diz: “(...) ca el é ora o escolheito que nom há par entre todo os cavaleiros que ora sam nem foram gram tempo há" (p. 54). Durante a aventura do mosteiro, novamente um ermitão associa-o, agora de forma mais literal, à figura de Cristo, apontando as profecias de sua vinda. Entende-se claramente pela fala do ermitão ser Galaaz um "novo Cristo":

E assi como os profetas, gram tempo ante da viinda de Jesu Cristo, profetizarom sua viinda, e o que ele livraria o poboo das coitas do inferno, bem assi profetizaram os santos ermitães e outrossi muitos homees bõõs vossa viinda mui gram sazom ante que vós viéssedes. (p. 61)

Sua entrada na sala em que estão reunidos os cavaleiros da Távola Redonda é, da mesma forma, marcada por uma série de dados sobrenaturais, semelhantes aos que marcarão, mais à frente, a aparição maravilhosa do Santo Graal. Apesar de todas as portas e frestas do paço cerrarem-se sozinhas, ainda assim este não escurece porque "entrou i uu tal raio de sol". Este raio precede a entrada triunfal de Galaaz. Sabemos que, entre outros, Cristo está associado ao simbolismo solar. Do mesmo modo, Galaaz tem luz própria e será também a luz do caminho até o Graal.

Como Cristo, Galaaz também é tentado. Na DSG, a preocupação com a luxúria que impera na Ordem da Cavalaria, em que os pecados da carne são os grandes e principais impecilhos para a ascese dos cavaleiros, o diabo assu-

\footnotetext{
"Retoma-se a querela do arbítrio e da predestinação: sendo Deus misericordioso, escolheu um pecador para se fazer representar e exercer justiça (...) Assim, Galaaz é "sergente de Jesus Cristo”, instrumento da Providência Divina, em quem simultaneamente se realiza o cancro do pecado e a graça da absolvição” (MONGELLI, 1995, p. 63).
} 
me a forma de uma donzela que, sob o impacto da beleza do herói, se apaixona perdidamente por ele e deseja tentá-lo em seu leito. O episódio da tentação de Galaaz pela filha de Brutus é emblemático do paradigma que a obra busca construir entre o herói e Cristo ${ }^{6}$. Também Galaaz deve ser testado, também ele deve resistir às malícias e às astúcias do demônio para cumprir seu percurso até a ascese plena, que se dará no encontro com o Santo Graal.

A partir de determinado momento da narrativa, Galaaz também começa a operar milagres, como a expulsão do diabo do corpo da donzela possessa, o desmascaramento do demônio disfarçado no "encantador" que acompanha o Rei Peles, a cura do aleijado na entrada da cidade de Sarras, entre outros. Como se observa, milagres semelhantes e, poderíamos dizer, espelhados naqueles que operou Cristo, conforme os relatos dos Evangelhos.

Conforme afirma Mongelli, "a trajetória de Galaaz é uma seqüência de sucessos” Estes serão coroados com sua contemplação do Santo Graal e, após sua morte, com sua ascensão ao céu, como o modelo sobre o qual se constrói. Galaaz perfaz assim as exigências necessárias para a conformação de "sua natureza de Cristo renovado" (MONGELLI, 1995, p. 70-73). Ainda que não consiga redimir e salvar o reino de Logres, todo entregue aos pecados da luxúria, da soberba e da inveja, ele apresenta-se como modelo perfeito de ascese espiritual e individual, corroborando o caráter doutrinário cristão da novela portuguesa.

3.

Outra novela portuguesa, agora nossa contemporânea, constrói sua personagem central sobre o mesmo modelo mítico de Cristo. Jorge de Sena, em seu $O$ físico prodigioso, de 1966, revisita o mundo e o imaginário medievais $^{7}$ para nos contar as andanças de um Físico. Criada "como símbolo da

\footnotetext{
Para uma análise mais detalhada e inteligentemente sugestiva do episódio, remetemos o leitor para o capítulo III, primeira parte, do livro de MONGELLI, 1995.

7 Jorge de Sena em notas finais à edição d'O físico prodigioso, afirma ser sua obra um "desenvolvimento muito ampliado e, se quiserem, muito deturpado de dois "exemplos" do Orto do esposo, o belo livro moralístico-religioso da literatura portuguesa da primeira metade do século XV" (SENA, 1986, p.145). A partir deste ponto passaremos a denominar O físico prodigioso pela sigla FP, para efeito de concisão do trabalho.
} 
liberdade e do amor" (SENA, 1986, p. 9), a novela apresenta a peregrinação do Físico, que trilhará um percurso em muito semelhante ao de Cristo, e por sua vez ao de Galaaz, mas que em determinado momento será desvirtuado do caminho seguido por aqueles.

O motivo do desvirtuamento o próprio autor já indica na "nota introdutória” à edição independente, apontando não só aquela simbologia de que falamos acima, como também assumindo ter conferido um caráter erótico e revolucionário à novela. Tratando do moralismo da sociedade portuguesa à época da publicação do conto na coletânea Novas andanças do Demônio, de 1966, Sena afirma que "o descarado pan-erotismo do "físico" podia chocar, caso a não chocassem (a sociedade) as implicações fundamente revolucionárias e subversivas da narrativa inteira" (Idem, p. 10).

Não bastasse esta "subversão" temática amorosa, o autor ainda denuncia plena consciência de ter construído sua novela sob o signo de outra rebeldia, a formal: “... o experimentalismo narrativo, jogando com o espaço, o tempo, a repetição variada do texto, etc., é uma das bases essenciais desta novela, como o é a Idade Média ou algo semelhante, fantástica, em que a situei” (Idem, p. 12).

Como se percebe, estão aqui já anunciados os elementos motivadores do desvirtuamento do modelo a que nos referimos acima. Todavia, interessa-nos, mais do que constatar o apartamento do modelo e os componentes provocadores deste, analisar de que maneira o modelo mítico de Cristo é retomado por Sena e de que forma sua narrativa avança, em relação à DSG, na utilização deste. Observemos, para tanto, a peregrinação deste Físico dito prodigioso.

A novela começa com o Físico interrompendo sua caminhada para banhar-se em um rio. Ao se por nu para entrar na água, é assediado por uma figura invisível que goza de seu corpo. Logo ficamos sabendo que se trata do diabo, com quem o Físico tem um pacto, estabelecido por sua madrinha que, ao lhe dar um gorro mágico, convocou o diabo para que este desse poderes sobrenaturais ao seu afilhado. Desde então, aceito o acordo, sempre que sozinho e nu a cena se repetia.

Depois de servido o diabo, o Físico banha-se no rio para se limpar das marcas daquela relação que lhe causa tédio e certo nojo. Logo após, deita-se à beira do rio. Neste momento, aparecem três donzelas que, tendo travado comunicação com ele, identificam marcas (formoso, físico e virgem) que o caracterizam como o "esperado", aquele que virá salvar-lhes a senhora por 
quem choram, doente e desenganada à espera de seu salvador no castelo. Utilizando-se de seus poderes mágicos, o Físico cura a rainha com um banho feito a partir de seu próprio sangue.

Mário Martins interpreta desta forma este episódio, que tem como fonte, como vimos, o Orto do esposo: "Este castelo simboliza a Igreja. As três donzelas chamam-se Fé, Esperança e Caridade. Choram por causa da humanidade, a castelã doente pelo pecado e a ponto de morrer. Veio por fim Jesus. As três virtudes... meteram-no na Igreja, para curar a todos no banho do sangue de seu coração trespassado" (MARTINS, apud FAGUNDES, 1981, p. 135). ${ }^{8}$ Vê-se desta maneira a associação da figura do Físico com Cristo. Não param aí as semelhanças. Fagundes aponta ainda a missão do Físico: "disseminar amor, curar enfermos e ressuscitar mortos" (FAGUNDES, 1981, p. 135). Além disso, sua presença representa uma ameaça às normas e às instituições vigentes. Não por outro motivo, ele será denunciado à Inquisição por uma espécie de Judas, o Capelão do Castelo.

Fagundes chama também atenção para a subdivisão simbólica do desenvolvimento da narrativa entre os doze capítulos: seis capítulos para a criação (encontro, cura e amor) e outros seis para a destruição (prisão, paixão e morte) (Idem, p. 135). Por fim, o Físico vive uma "paixão" em muito semelhante à de Cristo: arrasta-se pelas ruas, há um cortejo que o segue, algumas mulheres saem à rua a limpar seu sangue e, após sua morte, uma roseira e um novo físico surgem de sua sepultura, como a anunciar a ressurreição.

Os elementos de cristologia na caracterização do Físico são evidentes e nos permitem ver renovados aqueles ideais que presenciamos na peregrinação de Galaaz na DSG. No entanto, as semelhanças se encerram por aqui.

4.

Como vimos, a orientação que Jorge de Sena dá à sua novela é de teor revolucionário e erótico. Consoante a definição de Batailles, "o domínio do erotismo é o domínio da violência, o domínio da violação” (BATAILLES,

8 Seguiremos, a partir daqui, o levantamento dos elementos semelhantes e distintos de cristologia presentes n’O físico prodigioso, identificados por Francisco Cota Fagundes. 
1987, p. 16). A partir do capítulo sete da novela, toda a narrativa enceta um caminho pela violência. Acusado de compactuar com o demônio, o Físico é preso, julgado e condenado. Sua morte na forca só não se dá por interferência de seu protetor, o diabo ${ }^{9}$. Sua "via crucis", todavia, promove uma verdadeira revolução, já que o castelo e a cidade são tomados pelo fogo, ocorrem tumultos, assaltos, e - de acordo com a subversão típica provocado pelo registro carnavalizado da paródia - "no meio, porém, de aquilo a população vivia num delírio de prazeres, em festa” (SENA, 1986, p. 135).

A este contexto podemos relacionar uma daquelas "transposições simbólicas" da figura mítica de Cristo de que fala Dabezies. Uma transposição possivel é justamente identificar Jesus com os ideais de um grupo social oprimido. O fogo, a festa, a peste, enfim, todos os acontecimentos que parecem oriundos da peregrinação do Físico resultam em profundas transformações na sociedade. Diferentemente da DSG, em que as ações de Galaaz revertem em proveito individual, contribuem quase que exclusivamente para sua ascese pessoal e, no máximo, para a reiteração de um modelo perfeito de cristão, o deslocamento do físico para o interior da comunidade promove mudanças significativas para esta. Resulta em subversão, rebeldia, liberdade.

Do mesmo modo, para Bataille o erotismo traz em si também a aura da subversão. Identificamos imediatamente este caráter subversivo na relação que se estabelece entre o Físico e a cortesã. Se era necessário que o "desejado", aquele que viria curá-la, fosse virgem, portanto puro e casto, como se espera de um ser capaz de operar curas/milagres, esta mesma cortesã põe fim à virgindade do Físico, como se para que a cura acontecesse fosse necessário sacrificar sua castidade. Lembre-se que a castidade é, na DSG, um dos valores maiores de cavaleiros como Galaaz e Boorz e que o pecar contra a carne é a acusação mais constante feita aos guerreiros de Artur.

A relação que se estabelece entre cortesã e Físico, a partir da cura daquela, é de intensa paixão, paixão que levará ambos a morte. Se entendermos erotismo como um impulso que leva dois seres descontínuos a se unirem no intuito de encontrar a continuidade, ainda que disso resulte a morte de am-

9 Registre-se aqui uma diferença fulcral entre Galaaz e o Físico: a perseverança, a fé, os poderes daquele advêm de Deus; a força e os poderes deste, ao contrário, advêm diretamente do diabo. 
bos (BATAILLES, 1987, p.14), compreendemos que o encontro dos dois é altamente subversivo, pois ainda que os leve à morte, estabelece pela via erótica a continuidade, a esperança implícita no ato subversivo: a roseira e o novo físico que nascem do túmulo dos amantes.

Esta "continuidade erótica", a nosso ver, ilustra com clareza a defesa da liberdade e força do amor que desejou Sena representar em sua novela. Retomando um tema caro ao imaginário medieval - e não só a ele -, aquilo que Dabezies chama de "cristologia poética", o autor reitera alguns de seus aspectos, mas inova, pela via da desconstrução mítica, outras tantas de suas características.

Assim, ao dialogar com a tradição literária de seu país, Jorge de Sena parece ter consciência do que afirma Eliot, sobre o escritor e a tradição que o conforma, em seu "Tradição e talento individual": "o passado dev(e) ser modificado pelo presente tanto quanto o presente (deve estar) orientado pelo passado" (ELIOT, 1962, p. 40).

\section{BIBLIOGRAFIA}

A demanda do Santo Graal. Ed. de Irene Freire Nunes. Lisboa: INCM, 1995.

BAKHTIN, Mikhail. A cultura popular na Idade Média e no Renascimento: o contexto de

François Rabelais. Trad. de Yara F. Vieira, 2. ed., São Paulo/Brasília, HUCITEC/

Editora da Universidade de Brasília, 1993.

BATAILLE, Georges. O erotismo. Trad. de Antônio C. Viana. Porto Alegre: L\&PM, 1987.

BOLTON, Brenda. A reforma na Idade Média: século XII. Lisboa: Edições 70, 1986.

BRANCO, Lúcia Castello. $O$ que é erotismo. São Paulo: Brasiliense, s/d.

DABEZIES, André. “Jesus Cristo na literatura”. In: BRUNEL, Pierre (org.). Dicionário de

mitos literários. 2 ed. Rio de Janeiro/Brasilia: José Olympio/Ed. da UNB, 1998. p.517-523

DUBY, George. São Bernado e a arte cisterciense. São Paulo: Martins Fontes, 1988.

ELIOT, T. S. “A tradição e o talento individual”. In.: Ensaios de doutrina crítica. Lisboa: Guimarães, 1962.

FAGUNDES, F. C. "O artista com um malho: uma leitura d" $O$ físico prodigioso". In.:

SHARRER, H. L. \& WILLIAMS, F. G. (org.) Studies on Jorge de Sena. Santa Barnara:

University of California, 1981. p. 133-141.

FARIA, Eduardo. "Recensão crítica de O físico prodigioso". In.: Estudos sobre Jorge de Sena. Org. e introd. de Eugênio Lisboa: IN/CM, 1984. P. 377-379. 
LOPES, ÓSCAR. "Os contos de Jorge de Sena: problemas de assumido realismo”. In.: Estudos sobre Jorge de Sena. Org. e introd. de Eugênio Lisboa: IN/CM, 1984. p.319-337.

LOURENÇO, Eduardo. “Jorge de Sena e o demoníaco”. In.: Estudos sobre Jorge de Sena. Org. e introd. de Eugênio Lisboa: IN/CM, 1984. p. 49-59

LOYN, H. R. (org.) Dicionário da Idade Média. 2 ed. Rio de Janeiro: Jorge Zahar, 1991.

MARINHO, M. F. "O físico profigioso: o outro e o mesmo". In.: SHARRER, H. L. \& WILLIAMS, F. G. (org.) Studies on Jorge de Sena. Santa Barnara: University of California Press, 1981. p.142-151.

MEGALE, H. "Introdução". In.: A demanda do Santo Graal. Texto sob os cuidados de Heitor Megale. São Paulo: T. A. Queiroz, 1988. p. 1-21.

- O jogo dos anteparos: A demanda do santo Graal: a estrutura ideológica e a construção da narrativa. São Paulo: T. A. Queiroz, 1992.

MOISÉS, Massaud. Dicionário de termos literários. 6 ed. São Paulo: Cultrix, 1992.

MOngelli, L. M. de Medeiros. Por quem peregrinam os cavaleiros de Artur. Cotia: Íbis, 1995.

NOGUEIRA, Carlos R. F. O diabo no imaginário cristão. São Paulo: Ática, 1986.

Orto do Esposo. Ed. crít., intr. e gloss. de Bertil Maler. Rio de Janeiro/Stockolm: Instituto Nacional do Livro/Almquist Wihkselll, 1956-1964, 3 vols.

SENA, Jorge. O físico prodigioso. 4 ed. Lisboa: Edições 70, 1986.

VAUCHEZ, André. A espiritualidade na Idade Média Ocidental: séculos VIII a XIII. Trad. de Lucy Magalhães. Rio de Janeiro: Jorge Zahar,1995. 